\title{
PANCASILA SEBAGAI DARUL AHDI WA SYAHADAH DALAM HIMPITAN AMBIGUITAS POLITIK DAN URGENSI USWAH POLITIK
}

\author{
Ian Zulfikar', Ma'mun Murod Al-Barbasy ${ }^{2}$ \\ ${ }^{1}$ Program Studi Ilmu Politik, Universitas Nasional \\ ${ }^{2}$ Program Studi Ilmu Politik, Universitas Muhamadiyah Jakarta \\ email : ian.zulfikar@civitas.unas.ac.id, mamun.murod@umj.ac.id
}

Korespondensi : ian.zulfikar@civitas.unas.ac.id

\begin{abstract}
The Pancasila debate as an ideology of the country accompanied the long journey of the Indonesian nation. Muhammadiyah offers a new formula related to Pancasila by calling it Darul Ahdi wa Syahadah, a consensus and witness state. The mention of Pancasila as Darul Ahdi wa Syahadah is an affirmation to strengthen the position of Pancasila as the state ideology. Political reality becomes so pragmatic because political morality is "ambiguous". Even sadder, immoral political behavior and sticking with abuse of power is actually done by making the Pancasila as a cover or cover. Mental revolution requires fundamental changes that involve material, mental, cultural and political revolutions. The basis and direction of this mental revolution is the value of the Pancasila, especially those contained in the first, second and third precepts. The most important thing in carrying out the Mental Revolution is the need for political ideology (uswah). Uswah gives a lot of examples in religion, an example in terms of moral integrity, which includes the exemplary in establishing a relationship with power.
\end{abstract}

Keywords: pancasila, mental revolution, political ambiguity, political schools, the urgency of uswah politics

\begin{abstract}
Abstrak
Perdebatan Pancasila sebagai ideologi negara mengiringi perjalanan panjang bangsa Indonesia. Muhammadiyah menawarkan rumusan baru terkait Pancasila dengan menyebutnya sebagai Darul Ahdi wa Syahadah, yaitu negara konsensus dan negara kesaksian. Penyebutan Pancasila sebagai Darul Ahdi Wa Syahadah merupakan penegasan untuk memperkuat posisi Pancasila sebagai ideologi negara. Realitas politik menjadi begitu pragmatis lantaran moralitas politik yang "mendua" (ambigu). Lebih menyedihkan lagi, perilaku politik amoral dan lekat dengan abuse of power justru dilakukan dengan menjadikan Pancasila sebagai kedok atau tameng berlindung. Revolusi mental menghendaki adanya perubahan mendasar yang melibatkan revolusi material, mental kultural, dan political. Dasar dan haluan revolusi mental ini adalah nilai Pancasila, terutama yang terdapat dalam sila pertama, kedua, dan ketiga.Yang paling penting dalam melakukan Revolusi Mental adalah perlunya keteladanan (uswah) politik. Uswah memberikan banyak keteladanan dalam beragama, keteladanan dalam hal integritas moral, yang termasuk di dalamnya adalah keteladanan dalam menjalin relasi dengan kekuasaan.
\end{abstract}


Kata kunci: pancasila, revolusi mental, ambiguitas politik, uswah politik, urgensi uswah politik

\section{PENDAHULUAN}

Perdebatan Pancasila sebagai ideologi negara mengiringi perjalanan panjang bangsa Indonesia. Dimulai sejak persidangan BPUPKI yang menghasilkan gentlemen agreement berupa Piagam Jakarta (Wirjosanjojo, 1982). Berlanjut pada persidangan PPKI yang menghasilkan sila-sila Pancasila, Pembukaan dan Pasal 29 UUD 1945 sebagaimana dikenal saat ini, yang berbeda dengan rumusan Piagam Jakarta, 22 Juni 1945. Persidangan Majelis Konstituante di Bandung tahun 1956 sampai keluarnya Dekrit Presiden 5 Juli 1959 juga energi terbesar persidangan digunakan untuk membahas ideologi negara. Keluarnya Dekrit Presiden yang mengakomodir usulan beberapa Kiai Nahdlatul Ulama (NU) juga menyiratkan adanya perdebatan ideologi yang belum usai. Dalam Dekrit Presiden 5 Juli 1959, Soekarno masih menyebutkan kalimat: "Bahwa kami berkeyakinan bahwa Piagam Jakarta tertanggal 22 Juni 1945 menjiwai Undang-Undang Dasar 1945 dan adalah merupakan suatu rangkaian kesatuan dengan Konstitusi tersebut” (Zuhri, 1987).

Sekarang perdebatan ideologis tersebut sudah usai. Muhammadiyah mempunyai andil besar dalam menyudahi perdebatan panjang ideologi tersebut. Dalam perdebatan di seputar asas tunggal Pancasila awal 1980-an, Muhammadiyah dapat menerima dan menyepakati asas tunggal Pancasila melalui Muktamar Surakarta 1985 (Harun, 1986).

Awal Reformasi di saat terjadi Amandemen atas UUD 1945, Muhammadiyah tidak bersetuju atas usulan beberapa elemen umat Islam, termasuk PPP dan PBB yang mencoba berjuang mengembalikan Piagam Jakarta. Muhammadiyah termasuk yang menyetujui agar Sila Pertama Pancasila, Pembukaan Alinea dan Pasal 29 Ayat 1 UUD 1945 tetap dalam posisi status quo, sebagaimana rumusan Pancasila tanggal 18 Agustus 1945 (Murod, 2018).

Melalui Muktamar Makassar 2015, Muhammadiyah menawarkan rumusan baru terkait Pancasila dengan menyebutnya sebagai Darul Ahdi wa Syahadah, yaitu negara konsensus dan negara kesaksian. Penyebutan Pancasila sebagai Darul Ahdi wa Syahadah merupakan penegasan untuk memperkuat posisi Pancasila sebagai ideologi negara (Murod, 2014).

\section{Negara Dalam Terminologi Fiqh Siyasah}

Dalam terminologi figh siyasah dikenal beragam istilah negara (dar), di antaranya Dar al-harb,yang secara sederhana dipahami sebagai negara kafir yang sah secara syar'i untuk diperangi. Negara di mana tidak ada ikatan dengan negara Islam suatu ikatan perjanjian damai maupun perjanjian gencatan senjata dan tidak mesti disyaratkan negara tersebut melancarkan peperangan (terhadap Islam dan kaum Muslimin). Bahkan sudah cukup dengan tidak adanya ikatan perjanjian damai dengan nagara Islam sebagaimana yang telah kami sebutkan, maka sah bagi kaum muslimin memerangi penduduk negara ini kapan saja mereka mau. Dari sinilah 
negeri itu dinamakan darul harb (negeri yang syah secara syar'i untuk diperangi) (Pulungan, 1995).

Kalau merujuk pada pendapat Abu Hanifah, darul harbi disebut sebagai negeri yang harus diperangi (darul harb) dengan tiga ciri. Pertama, sistem keamanan di negeri itu dikontrol oleh orang-orang kafir. Kedua, tampilnya hukum-hukum kufur diberlakukan di sana menggantikan posisi hukum Islam. Ketiga, negeri itu telah bersambungan dengan negeri kufur dan susah dijangkau kaum muslimin. Berikutnya Darul Kuffar, negara yang di dalamnya diterapkan hukum-hukum kufur dan keamanan negara tersebut berada di bawah keamanan bukan Islam atau tunduk kepada negara kafir.

Darul Islam, negara yang dikuasai oleh umat Islam dan hukum Islam pun diterapkan. Bahkan kalau merujuk pada keputusan hasil Muktamar NU Banjarmasin 1936, Indonesia hingga saat ini tetap dianggap sebagai "Negara Islam". Keputusan Muktamar Banjarmasin disebutkan bahwa sesungguhnya negara Indonesia adalah Negara Islam karena pernah dikuasai sepenuhnya oleh orang Islam. Walaupun pernah direbut oleh kaum penjajah kafir (Belanda), tetapi nama Negara Islam masih selamanya, sebagaimana keterangan dari kitab Bughyatul Mustarsyidin yang menyebutkan bahwa "Setiap kawasan di mana orang Muslim mampu menempati pada suatu masa tertentu, maka kawasan itu menjadi daerah Islam, yang ditandai dengan berlakunya hukum Islam pada masanya. Sedangkan pada masa sesudahnya, walaupun kekuasaan Islam terputus oleh penguasaan orang-orang kafir (Belanda) dan melarang mereka untuk memasukinya kembali dan mengusir mereka. Jika dalam keadaan seperti itu, maka dinamakan Darul Harb hanya merupakan bentuk formalnya, tetapi bukan hukumnya.

Selanjutnya Dar al-Sulh, negara non-Muslim yang terikat perjanjian damai dengan Negara Islam. Dar al-salam, negeri yang digambarkan al-Qur'an sebagai baldatun thayyibatun wa rabbun ghafur; dan terakhir istilah dar al-ahdi wa alsyahadah.

Dalam konteks keindonesiaan, di lingkup umat Islam terjadi polarisasi terkait konsep kenegaraan ini. Dalam UUD 1945 bab 1 pasal 1 ayat 1 dinyatakan bahwa Negara Indonesia ialah Negara Kesatuan yang berbentuk Republik. Berbeda dengan deklarasi proklamasi Negara Islam Indonesia (NII) pimpinan Sekarmadji Maridjan Kartosoewirjo pada 7 Agustus 1949. Dalam Qonun Asasi NII bab 1 pasal 1 ayat 1 dinyatakan bahwa "Negara Islam Indonesia adalah negara Kurnia Allah SWT kepada bangsa Indonesia". Ayat 3 "negara menjamin berlakunya syari'at islam di dalam kalangan kaum muslimin". Berbeda pula dengan konsep Jama'ah Islamiyyah dalam Nidhom Asasi bab 2, pasal 4 ayat 2, "Sasaran perjuangan Jama'ah ini adalah mewujudkan tegaknya Daulah Islamiyyah sebagai basis menuju wujudnya kembali Khilafah 'Ala Minhajin Nubuwwah".

Sementara Hizbut Tahrir mengartikan Negara Islam adalah negara yang di dalamnya diterapkan hukum-hukum Islam dan keamanan negara tersebut berada di bawah keamanan Islam. Baik NII, Jama'ah Islamiyyah, Hizbut Tahrir maupun kelompok-kelompok Islam lainnya yang mengusung konsep negara Islam, Khilafah Islam atau Daulah Islamiyyah merupakan sebagian contoh dari mereka yang tidak puas dengan konsep bangsa Indonesia yang sekarang ini. 
Sementara Muhammadiyah sebagaimana tertera dalam Matan Keyakinan dan Cita-Cita Hidup (MKCH) pada poin ke-5 tegas dinyatakan :

"Muhammadiyah mengajak segenap lapisan bangsa Indonesia yang telah mendapat karunia Allah berupa tanah air yang mempunyai sumber-sumber kekayaan, kemerdekaan bangsa dan negara Rebuplik Indonesia yang berdasar Pancasila dan UUD 1945, untuk berusaha bersama-sama menjadikan suatu negara yang adil makmur yang diridloi Allah SWT, "Baldatun Thoyyibatun Warobbun Ghofur". (Pasha, 2000).

Perdebatan seputar ideologi negara antara kelompok Islam dan kelompok nasionalis sejak persidangan di BPUPKI, PPKI hingga di Majelis Konstituante berangkat dari pandangan yang berbeda mengenai hubungan antara agama dan negara. Kalangan kelompok Islam seperti Ki Bagus Hadikusumo (Muhammadiyah) dan KH. Wahid Hasjim (NU) merupakan wakil dari kelompok yang memiliki pandangan tidak terpisahkannya hubungan antara agama dan Negara (holistic). Sedangkan kelompok nasionalis memandang sebaliknya, yakni agama harus dipisahkan dari negara (Sitompul, 1989).

\section{Pancasila Sebagai Darul Ahdi Wa Syahadah}

Muhammadiyah memandang bahwa negara Pancasila merupakan consensus nasional dan tempat pembuktian atau kesaksian. Dar al-ahdi merupakan penegasan bahwa Indonesia lahir karena adanya kerelaan di antara para pendiri bangsa untuk menerima seluruh kemajemukan bangsa. Bukan hanya consensus, negara Pancasila juga merupakan dar al-syahadat atau "negara kesaksian" atau "negara perjanjian". Jadi selepas bersepakat mendirikan Indonesia yang berideologikan Pancasila, maka seluruh elemen bangsa harus mengisinya agar menjadi negara yang aman dan damai menuju kehidupan yang maju, adil, makmur, bermartabat, dan berdaulat dalam naungan ridha Allah Subhanalohu Wata'allah (Murod, 2014; Hidayat, 2016).

Muhammadiyah merasa penting untuk selalu menegaskan posisi Pancasila. Dalam pandangan Muhammadiyah, Pancasila sudah sesuai dengan nilai-nilai Islam dan merupakan titik temu seluruh komponen bangsa. Selain itu, fakta sejarah, Muhammadiyah sangat berperan penting dalam membuat rumusan final Pancasila sebagai dasar negara. Ki Bagus Hadikusumo yang saat itu menjabat Ketua PB (sekarang PP) Muhammadiyah, dengan kebijaksanaannya mengubah ketegangan tentang Piagam Jakarta menjadi konsesus bersama, dengan mengubah "Tujuh Kata" dalam Piagam Jakarta menjadi hanya Ketuhanan Yang Maha Esa. Sikap legowo Ki Bagus Hadikusumo juga bisa dimaknai sebagai penegasan sikap tengah (tawasuth) Muhammadiyah yang tidak cenderung ke salah satu kutub ekstrim, baik konservatif yang menginginkan negara Islam, maupun negara liberal-sekuler (Murod, 1999).

Sebagai elemen penting dalam perumusan ideologi negara, Muhammadiyah perlu menegaskan posisinya kembali atas negara Pancasila. Penegasan ini penting seiring dengan kecenderungan menguatnya perilaku dan praktek bernegara yang nyata-nyata bertentangan dengan Pancasila. Selain masalah separatisme, menguatnya ekstrimisme beragama, juga penyimpangan akut dalam praktek bernegara, yang tergambar dari rapuhnya rasa nasionalisme pada diri sebagian 
bangsa Indonesia, tak terkecuali di lingkup elit politik, lemahnya penegakkan hukum di mana hukum hanya tajam ke bawah dan tumpul ke atas, tingginya angka kejahatan ekonomi dan penyalahgunaan kekuasaan (abuse of power) yang setidaknya tergambar dari masih tingginya angka korupsi. Kehadiran Komisi Pemberantasan Korupsi nyaris tak membawa perubahan berarti dalam menurunkan kuantitas dan kualitas korupsi di Indonesia.

Melalui penegasan bahwa Pancasila merupakan dar al-ahdi wa alsyahadah, Muhammadiyah ingin mengajak seluruh elemen bangsa untuk berpijak pada prinsip dasar bahwa negara ini milik kita bersama, yang harus dibangun, diselamatkan, dan tak boleh dirusak.

\section{Moralitas Politik Yang Ambigu dan Abuse of Power Berkedok Pancasila}

Dalam perspektif klasik, politik dimengerti begitu luhur sebagai values, "apa yang seharusnya" (das sollen), yang bertujuan mewujudkan kebaikan bersama (public good, maslahat-i al-ammah). Namun dalam praksisnya (das sein) yang kerap muncul dan menjadi mainstream justru pemaknaan politik "tanpa nilai" (unvalued), yang berbicara soal "apa yang senyatanya", politik semata dimaknai secara pragmatis, politik yang ansich berorientasi kekuasaan, dan politik yang hanya dipahami sebagai "soal siapa mendapatkan apa, kapan, dan bagaimana" (Suseno, 1993)

Mainstream politik unvalued ini tumbuh begitu subur, tidak saja di lingkup elit politik, tapi juga di masyarakat. Tidak saja menjelang perhelatan politik seperti pemilu atau pilkada, dalam keseharian pun begitu mudah mendapati praktek-praktek politik unvalued. Dominasi politik unvalued ini membawa dampak ikutan yang begitu buruk. Realitas politik menjadi begitu pragmatis lantaran moralitas politik yang "mendua" (ambigu). Satu sisi elit berteriak soal moralitas, katakanlah dalam hal pemberantasan korupsi, namun di sisi lain, elit juga masuk dalam kubangan praktek korupsi tersebut. Sistem politik yang bobrok dan korup pun dibiarkan untuk tidak mengatakan sengaja diciptakan. Tidak ada niatan serius untuk memperbaiki sistem politik tersebut (Murod, 2014).

Begitu pun masyarakat. Satu sisi begitu kencang berteriak soal pemberantasan korupsi, mengkritisi pejabat yang korup baik di lingkup eksekutif, legislatif, yudikatif maupun birokrasi, namun di saat bersamaan juga begitu menikmati perilaku korup para pejabat melalui proposal yang diajukan, permohonan bantuan, menerima money politics dari kandidat atau kontestan pemilu yang dalam prakteknya juga begitu memprihatinkan ataupun hal lain yang potensial menyuburkan perilaku korup para pejabat. Dan perilaku atau moralitas politik yang ambigu ini akan semakin terasa ketika menjelang berlangsungnya perhelatan politik seperti pemilu, pilkada, pilgub maupun pilpres.

Moralitas politik yang ambigu ini menjamur dan merambah semua sendi kehidupan. Di lingkup elit, pelakunya bukan saja mereka yang memang mempunyai karaktek moral politik yang buruk, tapi juga yang dikategorikan sebagai "orang baik" yang mencoba melakukan perbaikan atas bangsa ini. Begitu juga di lingkup masyarakat, bukan hanya mereka yang memang bermental korup, tapi juga yang selama ini di (ber) lebelkan sebagai "orang baik". 
Saat ini, elit yang secara moral politik buruk dan keterlibatannya dalam dunia politik pun diyakini hanya akan membawa kerusakan (mafsadat), cenderung mengambil jalan pintas dan instan. Dalam kapasitas sebagai calon legislatif atau kandidat di jabatan eksekutif misalnya mereka tidak mau menyambangi konstituennya. Mereka lebih memilih jalan pintas untuk menggapai kekuasaan lewat relasi kuasa dengan misalnya KPU, PPK, atau siapapun yang dinilai bisa "menggelembungkan" atau "mengamankan" suara. Tentu politik jalan pintas ini tidak murah, pasti membutuhkan biaya politik yang cukup mahal. Lalu apa yang bisa diharapkan dari politisi yang seperti ini? Sementara elit yang dikategorikan "baik", yang selama ini telah mencoba menjalankan politik secara santun pun pada akhirnya tergoda untuk berbuat politik yang amoral.

Di masyarakat, moral politik yang ambigu juga sudah menjadi kelaziman. Satu sisi masyarakat lantang mengkritisi perilaku korup para pejabat, tapi di sisi lain juga menikmati hasil korupsi pejabat, yang telah mengakibatkan atau mengharuskan elit berbuat korup. Masyarakat seperti sudah tidak merasa bersalah (berdosa) lagi untuk misalnya menerima atau meminta politik uang kepada kandidat atau kontestan politik yang akan dipilihnya. Pada beberapa hal mungkin masih bisa dipahami, karena mereka meminta imbalan atas suara yang diberikannya. Ada semacam simbiosis mutualisme. Tapi saat ini, berkembang juga bentuk moralitas politik ambigu lainnya, yaitu "ambil uangnya jangan pilih orangnya." Sepintas sikap ini baik karena bermaksud memberikan hukuman kepada elit politik pelaku money politics. Namun dalam praktiknya, di saat yang bersamaan, masyarakat juga menerima pemberian money politics dari kandidat lain. Sikap politik seperti ini justru akan semakin melanggengkan politik yang amoral dan ambigu.

Lebih menyedihkan lagi, perilaku politik amoral dan lekat dengan abuse of power justru dilakukan dengan menjadikan Pancasila sebagai kedok atau tameng berlindung. Perilaku ini memiliki kemiripan dengan perilaku politik di masa Orde Baru. Seperti layaknya dan kebanyakan pejabat Orde Baru yang begitu fasih bicara dan teriak tentang dan merasa diri paling Pancasila, saat ini pun nuansa pejabat bermental Orde Baru masih cukup kuat. Banyak pejabat yang begitu fasih bicara Pancasila, namun di saat yang bersamaan mereka melakukan abuse of power yang tentu bertentangan dengan Pancasila.

Saat ini abuse of power merupakan fenomena yang dapat ditemui di semua ranah public. Sekadar contoh, mereka yang dipercaya memimpin partai politik "berhasil" menjadikan partai politiknya sebagai ajang untuk mengumbar ambisi politik dan meneguhkan kepentingan yang bersifat sesaat. Ketua umum partai politik dan elit partai lainnya pada banyak sudah diposisikan bak tuhan (sengaja huruf "t" kecil). Sejumlah figur yang berhasil terpilih untuk memimpin daerah memposisikan kekuasaan sebagai miliknya yang lalu dipergunakan untuk memenuhi ambisi dan nafsu kuasa diri dan kelompoknya yang sangat sempit, yang jauh dari kepentingan untuk terwujudnya kemaslahatan umum (maslahati al-ammah).Demikian pula, mereka yang memiliki jabatan di berbagai institusi public pun terjebak ke dalam perilaku-perilaku busukdengan memanfaatkan jabatan yang diembannya.

Ujung-ujungnya adalah terjadinya korupsi, kolusi, manipulasi, dan praktikpraktik kotor lainnya. Nyaris tidak ada satu pun lembaga yang bersih dari praktik 
jahat yang merugikan rakyat dan negara. Bahkan lembaga yang mengurus persoalan yang berkaitan dengan masalah keagamaan pun tak luput praktik-praktik yang merugikan masayarakat umum.

Ironisnya, masyarakat tampak membiarkan terjadinya praktik-praktik kotor itu. Bahkan tidak sedikit yang ikut andil memperparah dengan masuk ke dalam pusaran perilaku amoral ini melalui praktik-praktik kotor yang lain, Saat ini sikap permisif yang serba "membolehkan" tumbuh subur di masyarakat. Masyarakat bukan saja melakukan pembiaran tapi bahkan mengamini perilaku-perilaku amoral yang berwajah abuse of power. Sekadar contoh, masyarakat melakukan pembiaran dan bahkan mempersubur praktik "memperpendek jalan" dalam berurusan dengan birokrasi. Alasannya sederhana, daripada harus melalui jalan berliku-liku yang terkadang biaya yang harus dikeluarkan lebih banyak, maka mereka memilih untuk memotong jalur birokrasi untuk menghindari urusan yang menjadi berbelit-belit dan dipersulit oleh birokrasi. Sebagian birokrasi kita masih bermental: "kalau bisa dipersulit, kenapa dipermusah".

Nilai-nilai kejujuran, tanggung jawab, dan sejenisnya mulai menghilang berganti dengan menguatnya perilaku permisif, ambisi, dan kerakusan, dan pola hidup yang pragmatis yang memandang apapun akan dinilai baik ketika dapat menguntungkan diri (dan bahkan) kelompoknya.

Dalam praktek penyelenggaraan pemerintahan, entah sudah berapa puluh anggota DPR, DPRD, menteri, gubernur, bupati, walikota yang sudah dijebloskan ke penjara gara-gara korupsi, kolusi, suap, ataupun pemerasan. Jumlah pelaku "kejahatan publik" ini bukan malah semakin berkurang, tapi justru semakin bertambah dan jangkauan wilayahnya pun semakin melebar dan massif merembet ke tingkat desa seiring dengan adanya dana desa yang jumlahnya cukup fantastis.

Mengapa kecenderungan abuse of power semakin meningkat? Ada beberapa argumentasi yang bisa menjelaskan. Pertama, bobrok dan korupnya sistem politik yang ada saat ini, yang tergambar dari produk perundang-undangan dalam bidang politik, yang secara implisit maupun eksplisit mendukung tumbuh suburnya moralitas politik yang ambigu. Misalnya pemilihan serba langsung yang secara moralitas telah merubah mentalitas masyarakat menjadi pragmatis. Belum lagi soal suara terbanyak dalam pemilu legislatif juga telah secara masif ikut berperan atas rusaknya moralitas politik bangsa. Bayangkan, pemilu dengan suara terbanyak, maka siapapun kandidatnya asal mempunyai cukup modal (capital) materi, diyakini akan dengan mudah menggapai kekuasaan politik. Bandingkan dengan aktivis partai yang day to day mengurus partai dan meskipun ditempatkan di nomor 1, namun karena yang bersangkutan tidak mempunyai cukup modal materi, praktis nomor urut 1 yang dimilikinya tak akan terlalu berarti.

Terhadap bobrok dan korupnya sistem politik ini, tak terlihat sedikit pun adanya political will dari elit politik yang berkuasa untuk mengubahnya. Rumus suatu sistem politik dapat dikatakan baik atau buruk itu sederhana, yaitu dengan melihat produk atau output dari sistem politik tersebut. Kalau outputnya baik, maka hampir pasti sistem politiknya baik. Sebaliknya, kalau outputnya jelek, hampir pasti sistem politiknya pun buruk, dan produk atau output politik di Indonesia saat ini 
lebih dan bahkan sangat kuat menggambarkan buruknya sistem politik (Surbakti,1994).

Kedua, akibat buruknya sistem politik, praktek politik yang terjadi pun berbiaya sangat mahal. Karena sangat mahal, sementara manusia yang oleh Aristoteles disebut sebagai zoon politicon, maka berbagai carapun digunakan untuk untuk menggapai kekuasaan tersebut, termasuk dengan cara merampok atau menjarah kekayaan negara lewat "perselingkuhan" dengan pihak lain. Ketiga, politik hanya semata dimaknai sebagai perebutan kekuasaan. Kekuasaan politik dianggap segala-galanya. Karena segala-galanya, maka siapa pun dan dengan cara apa pun berusaha meraih kekuasaan tersebut. Dengan pemaknaan politik yang seperti ini, maka mereka tidak peduli lagi akan pentingnya moralitas dalam berpolitik. Keempat, bobroknya mentalitas birokrasi kita dari mulai tingkatan paling atas sampai birokrasi pada tingkat yang paling bawah. Bobroknya birokrasi kita juga impact dari abuse of power. Birokrasi rasional sebagaimana digambarkan oleh Weber seperti jauh panggang dari api. Birokrasi kita cenderung gemuk dan irasional. Belum lagi birokrasi kita juga selalu diseret-seret ke wilayah politik.

\section{Urgensi Uswah Politik Dalam Revolusi Mental Pancasila}

Terjadinya abuse of power tentu aneh bila dikaitkan dengan Revolusi Mental yang saat ini tengah digaungkan dan digalakkan oleh Presiden Jokowi. Apalagi kalau dikaitkan dengan nilai-nilai Pancasila, karena bicara Revolusi Mental berarti bicara juga tentang nilai-nilai yang terkandung dalam Pancasila. Revolusi Mental ini diorientasikan agar nilai-nilai Pancasila bisa menjiwai dan mendorong perubahan di bidang material dan politik yang sejalan dengannilai-nilai das sollen dari Pancasila (Latif, 2011).

Revolusi mental menghendaki adanya perubahan mendasar yang melibatkan revolusi material, mental kultural, dan political. Revolusi (basis) material diarahkan untuk menciptakan perekonomian merdeka yang berkeadilan dan berkemakmuran, berlandaskan usaha tolong menolong (gotong royong) dan penguasaan negara atas cabang-cabang produksi yang penting yang menguasai hajat hidup orang banyak. Sementara revolusi mental-kultural diarahkan untuk menciptakan masyarakat religius yang berprikemanusiaan, egaliter, mandiri, amanah, dan terbebas dari berhala materialisme-hedonisme, serta sanggup menjalin persatuan dengan semangat pelayanan. Sementara revolusi political, diarahkan untuk menciptakan agen perubahan dalam bentuk integrasi kekuatan nasional melalui demokrasi permusyawaratan yang berorientasi persatuan (negara kekeluargaan) dan keadilan (negara kesejahteraan). Revolusi politik ini bisa diwujudkan dengan pemerintahan negara yang melindungi segenap bangsa dan seluruh tumpah darah Indonesia, memajukan kesejahteraan umum, mencerdaskan kehiduan bangsa, dan ikut melaksanakan ketertiban dunia berdasarkan kemerdekaan perdamaian dan keadilan (Toha, 2003).

Tekait gerakan revolusi mental, tak hanya berhenti pada perubahan pola pikir dan kejiwaan saja, tetapi juga pada kebiasaan dan karakter yang menyatu antara pikiran, sikap dan tindakan sebagai suatu integritas. Dasar dan haluan revolusi mental ini adalah nilai Pancasila, terutama yang terdapat dalam sila 
pertama, kedua, dan ketiga. Dalam ketiga sila tersebut dinyatakan bahwa setiap manusia diciptakan oleh cinta kasih Allah, sehingga semua manusia sederajat yang melahirkan semangat mental egalitarianism. Setiap pribadi dimuliakan oleh Tuhan dengan bawaan hak asasi yang tidak bisa dirampas, hak milik, kehormatankemerdekaan dengan kedudukan yang sama di hadapan hukum. Fokusrevolusi mental Pancasila adalah mentalitas kemandirian, mentalitas gotong royong dan mentalitas pelayanan. Ketiga disebut tricita revolusi mental.

Akhir dari semuanya, yang paling penting dalam melakukan Revolusi Mental adalah perlunya keteladanan (uswah) politik. Harus diakui, yang tidak atau setidaknya sangat minim dalam konteks kehidupan berbangsa dan bernegara adalah uswah. Minimnyauswah, yang tidak saja hinggap di kalangan para politisi, tapi juga kalangan agamawan. Saat ini rasanya sulit menemukan keteladanan di kalangan para politisi, termasuk juga uswah di kalangan elit agamawan yang sanggup memberikan banyak keteladanan dalam beragama, keteladanan dalam hal integritas moral, yang termasuk di dalamnya adalah keteladanan dalam menjalin relasi dengan kekuasaan.

\section{SIMPULAN}

Melalui penegasan bahwa Pancasila merupakan darul-ahdi wa al-syahadah, Muhammadiyah ingin mengajak seluruh elemen bangsa untuk berpijak pada prinsip dasar bahwa negara ini milik kita bersama, yang harus dibangun, diselamatkan, dan tak boleh dirusak. Moralitas politik yang ambigu bukan hanya disebabkan oleh para elite politik, tetapi juga masyarakat yang memanfaatkan kemudahan \& keuntungan dari perilaku amoralnya elite politik. Dalam perbaikan perilaku diperlukan revolusi mental yang dikaitkan dengan nilai-nilai pancasila dengan cara meningkatkan keteladan (uswah) politik karena uswah berarti integritas moral dalam menjalani relasi dan kekuasaan.

\section{DAFTAR PUSTAKA}

Harun, Lukman. (1986). Muhammadiyah dan Asas Pancasila. Jakarta: Pustaka Panjimas.

Hidayat, Syamsul. (2016). Negara Pancasila Sebagai Darul 'Ahdi Wa Al-Syahadah: Wawasan dan Kontribusi Muhammadiyah Bagi NKRI, dalam Jurnal Pemikiran dan Gerakan Muhammadiyah Tajdida. Volume 14 Nomor 1 Juni hal. 12-17.

Latif, Yudi. (2011). Negara Paripurna: Historisitas, Rasionalitas dan Aktualitas Pancasila. Jakarta: Gramedia Pustaka Utama.

Magnis-Suseno, Franz. (1993). Etika Politik: Prinsip-prinsip Moral Dasar Kenegaraan Modern. Jakarta: Gramedia.

Martahan Sitompul, Einar. (1989). NU dan Pancasila. Jakarta: Sinar Harapan. 
Murod Al-Barbasy, Ma'mun. (2016). Islam dan Negara: Studi Kasus Perumusan Perda Nomor 12 Tahun 1999 Kota Tasikmalaya dan Peran Politik Muhammadiyah dan NU. dalam Disertasi, Program Doktor Ilmu Politik Universitas Indonesia.

Murod Al-Barbasy, Ma'mun. (2014). Moral Politik yang Ambigu. dalam Koran Sindo, 11 November.

Murod Al-Barbasy, Ma'mun, et. al. (2014). Radikalisasi Pancasila: Merekatkan Kebhinnekaan Bangsa dan Membendung Radikalisme Agama. Jakarta: Pusat Pengkajian MPR RI.

Murod Al-Barbasy, Ma'mun. (2018). Politik Perda Syariat: Dialektika Islam dan Pancasila di Indonesia. Yogyakarta: Suara Muhammadiyah.

Pasha, Musthafa Kamal, Adabi Darban. (2000). Muhammadiyah sebagai Gerakan Islam: dalam Perspektif Historis dan Ideologis. Yogyakarta: LPPI UMY, hal. 305-322.

Pulungan, J Suyuthi. (1995). Fiqh Siyasah : Ajaran, Sejarah dan Pemikiran. Jakarta: Radjawali Press.

Surbakti, Ramlan. (1994). Memahami Ilmu Politik. Jakarta: Grasindo

Toha, Miftah. (2003). Birokrasi dan Politik di Indonesia. Jakarta : Radja Grafindo Persada.

Wirjosanjojo, Sukiman. (1982). Hidup Itu Berjuang: Kasman Singodimejo. Jakarta: Bulan Bintang.

Zuhri, Saifuddin. (1987). Berangkat Dari Pesantren. Jakarta : Gunung Agung. 